age 7 months (IOR $5<10$ months). SCr was determined and preoperative and postoperative creatinine clearance $(\mathrm{ClCr})$ was estimated using Schwarz formula. During surgical repair and till the end of the first 24 hours urine was collected to measure $\mathrm{ClCr}$, using the difference in urine (UCr) and SCr concentrations. Urine output, body temperature, duration of aortic cross clamping and cardiopulmonary bypass was recorded.

Results Median intraoperative urine output was $2.4 \mathrm{ml} / \mathrm{kg} / \mathrm{h}$ (IOR $1.29<3.15 \mathrm{ml} / \mathrm{kg} / \mathrm{h}$ ). Intraoperative $\mathrm{SCr}$ rised to $35 \mu \mathrm{mol} / \mathrm{l}$ (IOR $27.5<50.5$ ) vs preoperative SCr $29 \mu \mathrm{mol} / 1$ (IOR $24<32.9$ ), $\mathrm{p}<0,0001$. GFR declined from preoperative $98.4 \mathrm{ml} / \mathrm{min} . / 1.73 \mathrm{~m}^{2}$ (IOR $89.6<$ 123.04 ) to intraoperative $39.8 \mathrm{ml} / \mathrm{min} . / 1.73 \mathrm{~m}^{2}$, (IOR $24.9<65.5$ ), $\mathrm{p}<0,0001$

Conclusion Open heart surgery in children has severe, but transient effect on expression of renal biomarkers. Before discharge from the hospital both biomarkers returned to normal values.

\section{SYSTEMIC INFLAMMATORY RESPONSE SYNDROME (SIRS), MULTIPLE ORGAN DYSFUNCTION SYNDROME (MODS) AND SEPSIS AFTER OPEN HEART SURGERY IN CHILDREN}

doi:10.1136/archdischild-2012-302724.1668

${ }^{1} \mathrm{~T}$ da Rocha, ${ }^{2} \mathrm{~A}$ Botta, ${ }^{2} \mathrm{LD}$ Mulle, ${ }^{2} \mathrm{C}$ Ricachinevsky, ${ }^{1} \mathrm{P}$ Carvalho. ${ }^{1}$ Uti Pediatrica Hospital Santo Antonio, Universidade Federal do Rio Grande do Sul; '2Uti Pediatrica Hospital Santo Antonio, Santa Casa de Misericórdia de Porto Alegre, Porto Alegre, Brazil

Background and Aim Circulatory bypass (CBP) causes SIRS and MODS and the study of this prevalence is rare.

Methods We retrospectively made a cohort of 121 children operated during August, 2008 to July, 2009 to study the prevalence of SIRS, MODS and sepsis after open heart surgery.

Results The median age, weigtht, CBP time and temperature during CBP were 9 months, $6 \mathrm{Kg}, 55$ minutes and $32^{\circ} \mathrm{C}$, respectively. We found $48 \%$ of septal defects. During the first hour in PCIU 50.4 (\%) had the SIRS criteria with hypothermia present in $96.7(\%)$. Hypothermia was most frequent during all postoperative days except the second when hyperthermia was present in 41.6 (\%) vs $29.1(\%)$ of hypothermia. The others SIRS criteria such as elevated respiratory rate, heart rate and leucocytosis were present in 81.3 to $91.7(\%), 25$ to $37.5(\%)$ and 25 to $76.5(\%)$ of children, respectively. MODS criteria were present in 22.3 (\%) at arrive in PICU. During next postoperative days, MODS was more frequent than SIRS as follows: in the first day 53.8 (\%) vs $32.2(\%)$, second 41.3 (\%) vs 39.7 (\%), third 29.8 (\%) vs $19.8(\%)$, forth $24.8(\%)$ vs 17.4 (\%) and fifth $24.8(\%)$ vs $13.2(\%)$. After the third, forth and fifth postoperative days $56.2(\%), 62(\%)$ and $69.4(\%)$ of children, respectively, did not have SIRS or MODS. Prevalence of sepsis was 27.7 (\%).

Conclusion After open heart surgery in children, SIRS and MODS are more frequent in first 48 hours than other diagnosis.

\section{PERIPHERALLY INSERTED CENTRAL CATHETER (PICC) RELATED SUPERIOR VENA CAVA SYNDROME POST PATENT DUCTUS ARTERIOSUS LIGATION}

doi:10.1136/archdischild-2012-302724.1669

${ }^{1} \mathrm{M}$ Boyle, ${ }^{2} \mathrm{M}$ Cotter, ${ }^{1} \mathrm{~N}$ McCallion, 'D Corcoran, 'A Foran. ' Neonatology; ${ }^{2}$ Haematology, Rotunda Hospital, Dublin, Ireland

Background and Aims To assess incidence, management and outcomes of Superior Vena Cava (SVC) syndrome in post PDA ligation patients in the Rotunda Hospital. PICC's are used routinely in postoperative paediatric cardiac patients. Following placement, catheter-related thrombosis occurs in $8 \%$ to $45 \%$ of paediatric patients. Although uncommon, resultant SVC syndrome significantly complicates management of premature infants.

Methods A retrospective chart review of infants undergoing PDA ligation from July 2011 to March 2012.
Results 5 patients had PDA ligation within the study period. Average gestation at birth was $25+4$ weeks and average birth weight was $0.754 \mathrm{~kg}$. Surgery was performed at an average weight of $1.027 \mathrm{~kg}$ and 26.8 days. 9 PICC lines were inserted; mean of 1.8 per patient with removal following a mean of 12.5 days. 2 cases of catheter related thrombosis, post PDA ligation, resulted in SVC obstruction. Both patients had a PICC in situ at the time of surgery, the other 3 patients did not have PICC access during surgery. SVC thrombosis was detected at a mean of 15 days post operatively. One affected patient died subsequently due to complications.

Conclusions Post-surgical catheter related thrombosis is well documented. SVC syndrome can infrequently result as a complication, which may cause severe respiratory compromise leading to high morbidity and mortality. As treatment of SVC syndrome is very difficult, especially in post operative patients and with a trend towards fewer PDA ligations, increased awareness in neonatal units may allow early diagnosis and thrombolytic therapy to prevent the progression of this syndrome.

\section{INTERNET ADDICTION AMONG CHILDREN IN FAMILIES OF HIGH SOCIOECONOMIC LEVEL AND THE EFFECTS OF FAMILIAL FACTORS}

doi:10.1136/archdischild-2012-302724.1670

'SM Kayıran, ${ }^{2} \mathrm{TT}$ Comert, ' $\mathrm{N}$ Kose, 'B Gurakan. ' ${ }^{1}$ American Hospital; ' 2 Aydın University, Istanbul, Turkey

Background and Aims Internet use has increased rapidly in Turkey, raising concerns about physical and mental health problems associated with Internet addiction in adolescents. This study sought to describe Internet use among children aged 10-16 years in Turkish families of high socioeconomic level, and to evaluate the effects of familial factors.

Methods A questionnaire based on the Internet Addiction Test (IAT) was administered to 329 parents in American Hospital in Istanbul during the September-December 2010.

Results Of children and adolescents included in the sample, $45.3 \%$ (n: 149) were females, and 54.7\% (n: 180) were males. According the reports of parents, $9.1 \%$ ( $\mathrm{n}$ : 30 ) of children and adolescents were Internet addicts.

Conlusions We found that gender, age, and Internet use frequency affected Internet addiction. Although the prevalence of Internet addiction is low among Turkish children, preventive and educational initiatives and the involvement of addiction experts are necessary to reduce the effects of this emerging phenomenon.

\section{THE RELATIONSHIP BETWEEN SLEEP PATTERN AND OBESITY IN CHILDREN'S OF TEHRAN CITY}

doi:10.1136/archdischild-2012-302724.1671

${ }^{1} \mathrm{~A}$ Saber Gharamaleki, ${ }^{2} \mathrm{~A}$ Zamani, ${ }^{3} \mathrm{M}$ Hosseini, ${ }^{4} \mathrm{~S}$ Abedymanesh, ${ }^{5} \mathrm{~K}$ Jaafarian. 'Faculty of Health and Nutrition, Students' Research Committee, Tabriz University of Medical Science, Tabriz; '2Department of Nutrition and Biochemistry; ${ }^{3}$ Department of Epidemiology and Biostatistics, School of Public Health, Tehran; ${ }^{4}$ Department of Nutrition and Biochemistry, Ahvaz Jundishapur Medical Sciences University, Ahvaz; ${ }^{5}$ Department of Nutrition and Biochemistry, School of Public Health, Tehran University of Medical Science, Tehran, Iran

Objective To determine the relationship of sleep duration and efficiency with obesity in Tehran city children's.

Methods This study was conducted in Tehran city with 270 children aged 6 to 9 years. Heights, Weight, were measured and Body mass index (BMI), was calculated. Directly measured height and weight data were used to define overweight and obesity according to the centers for disease Control and Prevention's (CDC) 2000 Growth Charts. Nocturnal sleep duration and sleep efficiency were recorded by the Actigraphy method. 